\title{
Correction to: Tailoring lifestyle interventions to low socio-economic populations: a qualitative study
}

\author{
Nia Coupe ${ }^{1 *}$, Sarah Cotterill ${ }^{2}$ and Sarah Peters ${ }^{1}$
}

\section{Correction to: BMC Public Health (2018) 18: 967. https://doi.org/https://doi.org/https://doi.org/ 10.1186/s12889-018-5877-8}

In the original publication of this article [1] there is an error in the citations of Tables 2 and 3. In this correction article the incorrect and correct citations are shown for clarity:

Incorrect:

Eight SUs had qualifications, with the highest being degree level (Table 1).

Another strength is that our study took place in a real world setting in a city which comprises of both deprived and affluent areas. Participants were from different teams and from a range of socio-economic areas across the city, which provided variability within the sample (see Table 3).

Both themes identified some ways in which lifestyle in terventions can be tailored to low SES populations in relation to facilitating delivery and supporting behavior change. A summary of these recommendations can be seen in Table 2.

\section{Correct:}

Eight SUs had qualifications, with the highest being degree level (Table 2).

Another strength is that our study took place in a real world setting in a city which comprises of both deprived and affluent areas. Participants were from different teams and from a range of socio-economic areas across the city, which provided variability within the sample (see Table 2).
Both themes identified some ways in which lifestyle interventions can be tailored to low SES populations in relation to facilitating delivery and supporting behaviour change. A summary of these recommendations can be seen in Table 3.

Tables 2 and 3 are also shown in the Correction article for reference. The original publication has been updated. The publisher apologizes to the authors and readers for the inconvenience.

\section{Author details \\ 'Manchester Centre for Health Psychology, School of Health Sciences, The University of Manchester, Manchester, UK. ${ }^{2}$ Centre for Biostatistics,} School of Health Sciences, The University of Manchester, Manchester, UK.

Received: 4 August 2018 Accepted: 17 August 2018

Published online: 28 September 2018

Reference

1. Coupe N, Cotterill S, Peters S. Screening for chronic kidney disease of uncertain aetiology in Sri Lanka: usability of surrogate biomarkers over dipstick proteinuria. BMC Public Health. 2018;18:967. https://doi.org/10.1186/ s12889-018-5877-8.

\footnotetext{
* Correspondence: nia.coupe@postgrad.manchester.ac.uk

${ }^{1}$ Manchester Centre for Health Psychology, School of Health Sciences,

The University of Manchester, Manchester, UK
} 
Table 2 Service User characteristics

\begin{tabular}{|c|c|c|c|c|c|}
\hline ID number & Age range & Occupation & Ethnicity & Highest qualifications & IMD decile \\
\hline SU1 & $75-79$ & Sales and customer service (Retired) & White British & None & 9 \\
\hline SU2 & $45-49$ & Skilled Trades & White British & NVQ level 3 & 3 \\
\hline SU3 & $60-64$ & Administrative and Secretarial (Retired) & White British & NVQ level 2 & 3 \\
\hline SU4 & $65-69$ & Administrative and Secretarial (Retired) & White British & Vocational & 9 \\
\hline SU5 & $70-74$ & Administrative and Secretarial (Retired) & White British & 1 A level & 1 \\
\hline SU6 & $80-84$ & Elementary (Retired) & White British & None & 1 \\
\hline SU7 & $70-74$ & Elementary (Retired) & White British & None & 3 \\
\hline SU8 & $65-69$ & Caring, leisure and other (Retired) & White British & Level 2 diploma & 10 \\
\hline SU9 & $60-64$ & Unemployed (Employment Support allowance) & White British & None & 2 \\
\hline SU10 & $70-74$ & Elementary (Retired) & White British & Degree & 2 \\
\hline SU11 & $55-59$ & Caring, leisure and other & Asian British & Level 2 & 3 \\
\hline SU12 & $65-69$ & Elementary (Retired) & White British & Vocational & 6 \\
\hline SU13 & $40-44$ & Unemployed (Employment Support allowance) & White British & None & 1 \\
\hline SU14 & $65-69$ & Manager (Retired) & White British & None & 1 \\
\hline
\end{tabular}

Table 3 Challenges identified and suggested tailoring for lifestyle interventions for socio-economically deprived populations

\begin{tabular}{|c|c|c|c|}
\hline & Themes identified & Suggestions for tailoring (data) & Further suggestions for tailoring \\
\hline \multirow[t]{3}{*}{ Managing diversity } & Meeting diverse needs & $\begin{array}{l}\text { - Focus on education and no pressure to } \\
\text { engage with tools for those with limited } \\
\text { knowledge and difficult to engage. }\end{array}$ & $\begin{array}{l}\text { - Separate groups for first time attendees with } \\
\text { focus on education, and then on-going weigh-in } \\
\text { and support groups for those who have previously } \\
\text { attended. }\end{array}$ \\
\hline & $\begin{array}{l}\text { Language and literacy } \\
\text { barriers }\end{array}$ & $\begin{array}{l}\text { - Visual aids e.g. fats, sugars and salt pots, } \\
\text { traffic light card. }\end{array}$ & $\begin{array}{l}\text { - More visually presented information rather than } \\
\text { reliance on written materials. }\end{array}$ \\
\hline & Cultural diversity & $\begin{array}{l}\text { - Target specific groups e.g. ethnicity, } \\
\text { religion, to allow for tailoring of content } \\
\text { and building relationships. }\end{array}$ & $\begin{array}{l}\text { - More community development and linking with } \\
\text { social housing. } \\
\text { - Ensure service deliverers are suitably trained to } \\
\text { deliver culturally sensitive information. }\end{array}$ \\
\hline \multirow[t]{3}{*}{$\begin{array}{l}\text { Working against } \\
\text { the environment }\end{array}$} & $\begin{array}{l}\text { Affordability; attendance } \\
\text { and adherence }\end{array}$ & $\begin{array}{l}\text { - Use health professional referrals to add } \\
\text { value to free course. } \\
\text { - Provide cost appropriate suggestions } \\
\text { e.g. local deals, cheap recipes. } \\
\text { - Linking with leisure facilities for special } \\
\text { offers. }\end{array}$ & $\begin{array}{l}\text { - Additional commitment element to course. } \\
\text { - Considerations for policy level e.g. food vouchers. }\end{array}$ \\
\hline & Access and availability & $\begin{array}{l}\text { - Recommend frozen and tinned fruit } \\
\text { and vegetables. } \\
\text { - Suggest best options for fast food e.g. } \\
\text { tomato rather than cream based curries. } \\
\text { - Signposting. } \\
\text { - Free leisure pass. }\end{array}$ & $\begin{array}{l}\text { - Consideration for policy level e.g. planning. } \\
\text { - Include strategies for replacing fast food e.g. cooking } \\
\text { own healthier versions. } \\
\text { - Interagency communication to identify gaps in } \\
\text { provision. }\end{array}$ \\
\hline & Life gets in the way & $\begin{array}{l}\text { - Planning meals. } \\
\text { - Damage limitation strategies e.g. knowing } \\
\text { what not to eat at parties. }\end{array}$ & $\begin{array}{l}\text { - Ensure easy to implement/ realistic goals. } \\
\text { - Strategies to encouraging partners and families to } \\
\text { support/ adopt changes. }\end{array}$ \\
\hline
\end{tabular}

